\title{
Modeled Impacts of Cover Crops and Vegetative Barriers on Corn Stover Availability and Soil Quality
}

\author{
Ian J. Bonner • David J. Muth Jr. • Joshua B. Koch • \\ Douglas L. Karlen
}

Published online: 19 February 2014

(C) The Author(s) 2014. This article is published with open access at Springerlink.com

\begin{abstract}
Environmentally benign, economically viable, and socially acceptable agronomic strategies are needed to launch a sustainable lignocellulosic biofuel industry. Our objective was to demonstrate a landscape planning process that can ensure adequate supplies of corn (Zea mays L.) stover feedstock while protecting and improving soil quality. The Landscape Environmental Assessment Framework (LEAF) was used to develop land use strategies that were then scaled up for five U.S. Corn Belt states (Nebraska, Iowa, Illinois, Indiana, and Minnesota) to illustrate the impact that could be achieved. Our results show an annual sustainable stover supply of 194 million Mg without exceeding soil erosion $T$ values or depleting soil organic carbon [i.e., soil conditioning index $(\mathrm{SCI})>0$ ] when no-till, winter cover crop, and vegetative barriers were incorporated into the landscape. A second, more rigorous conservation target was set to enhance soil quality while sustainably harvesting stover. By requiring erosion to be $<1 / 2 T$ and the SCI-organic matter $(\mathrm{OM})$ subfactor to be $>0$, the annual sustainable quantity of harvestable stover dropped to148 million Mg. Examining removal rates by state and soil resource showed that soil capability class and slope generally determined the effectiveness of the three conservation practices and the resulting sustainable harvest rate. This emphasizes that sustainable biomass harvest must be based on
\end{abstract}

\section{J. Bonner $(\bowtie)$}

Idaho National Laboratory Department of Biofuels and Renewable Energy Technologies, US-Department of Energy (DOE),

P.O. Box 1625, Idaho Falls, ID 83415-2025, USA

e-mail: ian.bonner@inl.gov

D. J. Muth Jr. J. B. Koch

Praxik, LLC, 2701 Kent Avenue, Suite 130, Ames, IA 50010, USA

D. L. Karlen

National Laboratory for Agriculture and the Environment, USDA-Agricultural Research Service (ARS), 2110 University Blvd., Ames, IA 50011-3120, USA subfield management decisions to ensure soil resources are conserved or enhanced, while providing sufficient biomass feedstock to support the economic growth of bioenergy enterprises.

Keywords Landscape planning · Landscape Environmental Assessment Framework (LEAF) - Soil conservation .

Soil quality $\cdot$ Bioenergy $\cdot$ Sustainable agriculture

\section{Introduction}

Corn stover (Zea mays L.) has been targeted as a primary herbaceous bioenergy feedstock in the USA because of its abundance and logistical infrastructure [1,2]. While the anticipated 2014 launch of three full-scale corn stover-based conversion facilities is encouraging for lignocellulosic biofuels, sustainable feedstock supplies must increase dramatically to achieve the national goal of 61 billion $\mathrm{L}_{\text {year }}{ }^{-1}$ of cellulosic derived fuel by 2022 [3]. To meet this demand, an estimated 242 million $\mathrm{Mg}_{\text {year }}{ }^{-1}$ of lignocellulosic biomass is required for conventional biochemical conversion process yielding $252 \mathrm{~L} \mathrm{Mg}^{-1}$ [4]. Concern regarding the ability to sustainably meet those biomass goals has generated considerable attention and led to conclusions that improved agronomic practices will be needed if biomass productivity is to be increased without negatively impacting soil quality [5-8].

Soil erosion and soil organic carbon are the two primary soil resource concerns associated with harvesting crop residues [9]. Therefore, agricultural management decisions must aim to minimize wind and water erosion while maintaining ecosystem benefits provided by crop residues $[10,11]$. Current conventional management of corn residue uses postharvest and preplanting tillage practices such as chisel-disking and/or field cultivation to break up the residue and mix it into the soil. Producer goals associated with these operations 
include (1) improving soil physical properties (i.e., disrupt areas compacted by combines, grain carts, or other operations), (2) hastening decomposition of crop residues thereby enhancing nutrient recycling, and (3) minimizing surface residue which can create cool, wet conditions during the next planting season [12]. The sustainability of these practices, however, is subject to considerable debate, as annual soil mixing promotes rapid loss of organic carbon [6, 13, 14]. Collection of residue suffers similar criticism as harvested material would no longer be present to protect against wind and water erosion or contribute to nutrient and organic matter cycling.

One agronomic strategy that can facilitate stover harvest without negatively impacting soil quality is simultaneous adoption of no-till methods. Stover harvest has been shown to have much less impact on soil quality than conventional tillage because it preserves belowground soil structure, subsurface biota, and some surface residue [14-16]. Field research continues to examine the physical, chemical, and biological implications of reduced or no-tillage coupled with corn stover harvest [17-19]. To evaluate the potential impacts of such practices on an integrated lignocellulosic feedstock supply chain, the total sustainable quantity of available biomass, assuming these practices are adopted, must be estimated. A useful and rigorous assessment of biomass availability with various tillage and other conservation practices requires a reliable and robust method to predict regional response to agronomic management decisions.

Taking advantage of existing and well-established cropland management resources, Muth et al. [20] developed and utilized an integrated modeling framework [the Landscape Environmental Assessment Framework (LEAF)] to calculate potential national biomass supply using available soil type, crop production, and land management data. Further use of this modeling framework and associated data management methodologies presents a unique opportunity to evaluate land management practices aimed at supplying biomass while enhancing soil quality and site productivity. More recently, Muth and Bryden [21] used LEAF to demonstrate a $50 \%$ increase in sustainably available biomass in Iowa if no-till practices were adopted. Earlier use of LEAF was complemented with the Policy Analysis System (POLYSYS) modeling framework [22], allowing for assessment of agronomic practice's impact on biomass availability and soil quality.

Reduced or no-tillage, planting of winter cover crops, and establishment of vegetative barriers are conservation practices that show great promise for reducing soil erosion and increasing soil organic carbon [10, 23-26]. Described in detail by English et al. [27], these three conservation practices can have significant impacts on farmer-perceived costs of residue removal, soil erosion, and ultimately their likelihood of participating in biomass supply programs. As the collection of biomass is often met with the stigma of potentially jeopardizing soil resources and environmental quality, adoption of conservation practices to mitigate erosion, pollution, and soil degradation risks is met with social acceptance and financial incentives that in many cases will be immensely important if a mature bioenergy industry is to be developed. Furthermore, incorporation of vegetative barrier strips composed of herbaceous perennial energy crops such as switchgrass (Panicum virgatum) or miscanthus (Miscanthus giganteus) could provide additional ecosystem benefits and serve as an additional feedstock supply if managed properly [28, 29].

The objective of this study is to utilize LEAF to evaluate the impact of conservation management practices (reduced and no-tillage, winter cover crops, and vegetative barriers) on biomass availability in the top five corn stover residueproducing states: Nebraska, Iowa, Illinois, Indiana, and Minnesota. Estimates of the quantity of sustainably available corn stover in this high-production region are projected in terms of soil quality, as defined by the predicted quantity of soil loss and changes in soil organic matter content with each management scenario or combination thereof. Furthermore, the effectiveness of each conservation management practice is compared to field specifics of (1) crop rotation, (2) soil capability class, and (3) slope under two sustainability goals. The data required to make these comparisons is readily available because this study executes LEAF for every Soil Survey Geographic database (SSURGO) soil map unit selected, each crop rotation, and each conservation management practice. These combinations provide a database of over 12 million records.

\section{Background}

This project utilizes an integrated data management and modeling framework currently known as LEAF to perform assessments and design alternate production systems. The development of LEAF has been described in detail by Muth et al. [20]. Briefly, the Revised Universal Soil Loss Equation 2 (RUSLE2) [30], the Wind Erosion Prediction System (WEPS) [31], and Soil Conditioning Index (SCI) [32] are used in an optimized manner with their inputs and outputs linked seamlessly through the framework. RUSLE2 simulates daily changes in soil water and temperature dynamics to estimate the impacts of water erosion processes. WEPS is a processbased daily time-step model that simulates wind erosion based on soil condition. The SCI value generated through RUSLE2 and WEPS is used to qualitatively describe whether soil organic matter is being increased, decreased, or sustained as a function of biomass input, erosion, and management 
operations. Further details on the function of each of these three major models, their use in LEAF, and examples of other published uses are discussed in Muth et al. [20].

LEAF has incorporated peer-reviewed, readily available data, assumptions, and models to perform assessments from the subfield $(<10 \mathrm{~m})$ to national scales [20,21]. The analysis approach is currently being validated through collaborative research with the USDA Natural Resources Conservation Service (NRCS) [33]. Assuming the NRCS approves the approach, long-term plans are to use LEAF to help develop conservation management plans for land from which corn stover will be harvested. LEAF also continues to be calibrated and verified using field trial data from the Regional Feedstock Partnership network [34]. The calibration and verification activities have also moved towards innovative agronomic management strategies and provide a key element for confidence in setting and achieving targets for sustainable feedstock supplies [35]. Finally, LEAF has also been used extensively to perform peer-reviewed analyses for two enabling agronomic management strategies: cover crops and vegetative barriers [27].

Environmental sustainability of the modeled agronomic practices was assessed by focusing on soil erosion and organic carbon. These two factors were chosen because, as previously discussed in relation to tillage and residue removal, soil erosion is consistently identified as a critical threat to soil quality [36]. Significant loss in productivity and soil quality will occur if soil erosion losses consistently exceed soil formation rates [37]. Therefore, the NRCS has developed standard approaches and tools to compare erosion levels to established tolerable soil loss levels $(T)$ at the soil survey map unit scale $[38,39]$. This project has incorporated those NRCS methods into LEAF, and therefore, all targets include criteria that restrict simulated soil erosion loss to levels less than previously established $T$ rates.

\section{Materials and Methods}

LEAF was applied to the top five corn stover-producing states (Nebraska, Iowa, Illinois, Indiana, and Minnesota [20]) to determine the impact of cover crops, vegetative buffers, and reduced tillage intensity on the amount of corn stover that can be sustainably harvested. Additionally, the five states used in this study have a significant amount of existing and ongoing field research that may be used to substantiate the modeled findings presented by this work. Details regarding the assessment methodology are available in Muth et al. [20] and Muth and Bryden [21]. Most parameters were unchanged and therefore are only briefly described in the following subsections. All additional considerations, assumptions, and methods modified for this study are described in full.
Soil Data

The SSURGO database [38] was used to provide soil data on a 10 to $100 \mathrm{~m}$ scale for defining spatial elements within the five states. The data used was a snapshot of the USDA-managed server from April 8, 2011 and was managed offline in a SQLite database [21]. Only soils with SSURGO land capability class ratings of 1 through 4 (those most suitable for agricultural production) were used for this study. Any soils occupying less than 405 ha in a county were not considered in order to increase computation speeds. With these assumptions, the approach accounted for more than $90 \%$ of land in row crop production in these states. The LEAF analysis was run independently for every selected SSURGO soil map unit in each county for the study's five states.

\section{Climate Data}

The modeling framework used three different climate data sources because of differences in the component models. RUSLE2 uses a set of spatially explicit databases managed by NRCS [30], while WEPS requires the CLIGEN daily climate generator and WINDGEN the daily wind speed and direction generator [31]. The integrated model identifies the county location for each SSURGO map unit and loads the required RUSLE2 climate data from the NRCS assembled dataset. CLIGEN and WINDGEN are stochastic models that utilize historic data to generate daily weather inventories for specified time periods. CLIGEN generates precipitation, minimum and maximum temperatures, solar radiation, dew point, wind speed, and wind direction as daily inventories for a specific geographic location. WINDGEN generates hourly wind speed and direction inventories that provide WEPS the wind event intensity data required to calculate erosion. As with RUSLE2, both CLIGEN and WINDGEN receive location information at the county level based on the SSURGO map unit and are used to create the datasets required for each LEAF analysis.

\section{Crop Rotations}

Three crop rotations for corn stover removal were considered: continuous corn, corn-soybean [Glycine $\max$ (L.) Merr.], and corn-corn-soybean. The USDA National Agricultural Statistics Service (NASS) Cropland Data Layer (CDL) [40] methodology developed by Muth et al. [20] was used to determine the area in each county managed under these rotations. Threeyear crop rotations for 2008, 2009, and 2010 were developed by overlaying the CDL data for each state. Data for all three years were spatially joined and intersected for every county in each state studied. The yearly land cover category for each $56 \mathrm{~m}$ grid cell was written to a database. All "like" grid cells were then aggregated. Any land areas that shifted from 
agricultural to nonagricultural uses were removed from the assessment. It is important to note that this study attributed all corn and soybean acres found in the five states to the three rotations listed previously. This is an important adaptation to the methodology developed by Muth et al. [20]. The results of the analysis are impacted by this assumption, particularly in states where corn is more commonly included in rotations with crops other than soybean. The land areas defined by each of the three crop rotations were used independently by LEAF to calculate sustainably available stover by crop rotation. The sum of all three rotations was used to quantify state-level biomass availability for each of the modeled simulations.

\section{Land Management}

Land management practices describe the crop(s) grown, their yield, fertilizer rates, and tillage practices, as well as interactions between those factors. Timing and type of equipment used for planting, tillage operations, grain harvest, and residue removal were determined by crop rotation and geographic location. Timing and order of field operations were based on NRCS crop management zones (CMZ) [41], an extensive soil and crop management operation and scenario database developed by NRCS. The five states in this analysis represent CMZs 1, 2, 4, 5, 16, 17, and 24. CMZs 4 and 16 comprise the majority of the area investigated. This information was used to build management and stover removal practices for each of the CMZs investigated.

\section{Tillage Practices}

Compared to Muth et al. [20], fewer tillage practices were modeled for this study. Conventional tillage was not included because (1) this study focused on identifying opportunities for conservation practices to support residue removal and (2) it was assumed that stover harvest would decrease residue management challenges currently faced by land managers that often lead to intensive tillage choices. The reduced tillage and notillage simulations were consistent with Conservation Technology Information Center (CTIC) [42] tillage definitions. The specific tillage equipment, dates of operation, and number of passes were established for each crop and tillage regime within every CMZ. This process created CMZ- and crop-specific rules for populating each crop rotation and tillage combination. Reduced tillage included at least one full-width tillage pass but left up to 15 to $30 \%$ residue on the soil surface after planting. No-till was defined as the minimum soil disturbance required for planting. A third "current" tillage practice was created by aggregating the reduced and no-tillage practices into an area-weighted average for each county. The assumptions for tillage management practices at the county level match those used for the U.S. Billion Ton Update [1], with the exception that conventionally tilled areas were mapped to reduced tillage practices in this study. Each of the tillage, cover crop, and vegetative barrier scenarios used in this study plus the Billion Ton Update and LEAF baseline scenarios are presented in Table 1.

\section{Residue Removal Practices}

The five residue removal methods developed by Muth and Bryden [21] were used for each combination of crop rotation and tillage practice. These included no residue harvest (NRH; $0 \%$ removal), harvest grain and cobs (HGC; $22 \%$ removal), moderate residue harvest (MRH; $35 \%$ removal), moderately high residue harvest (MHH; $52 \%$ removal), and high residue harvest (HRH; $83 \%$ removal). Each harvest method was simulated using currently available farm machinery, thus allowing the fractions of standing and laying residue to be estimated as well as the orientation of laying residue, which are important factors for accurately predicting both wind and water erosion [20].

\section{Grain Yield and Stover Quantity}

County average yields reported by NASS for 2008 to 2010 were used to establish county-level yield assumptions for residue-producing crops that match those used for the U.S. Billion Ton Update [1]. A 1:1 grain:residue ratio was assumed for all yields, such that any increase in yield would result in an equal increase in potentially available corn stover.

\section{Cover Crops}

This study extends the methodology developed by Muth et al. [20] by including a cover crop. A winter rye cover crop was applied to all crop rotations, even though there are a number of agronomic challenges that must be overcome within each of the five states before this practice will be routinely implemented without any negative impacts on grain production or harvest operations [43]. However, since this study's objective is to investigate potential impacts of cover crops on sustainable stover availability, challenges associated with implementing cover crops are not accounted for.

\section{Vegetative Barriers}

The work of Muth et al. [20] was further extended by including vegetative barriers modeled as a $3 \mathrm{~m}$ wide, single native perennial grass barrier located in the middle of each slope profile (Fig. 1). The standard representation and description of vegetative buffers from the RUSLE2 management database was used [30]. A wide range of representative slope lengths were modeled because of the broad geographic region represented by the study area. The use of only a single buffer for all slope lengths was done to simplify development and execution of the management practices. Therefore, this assumption 
Table 1 Total sustainable corn stover availability and average sustainable removal rates for the top five corn stover-producing states under the standard sustainability criteria (erosion $<T$ value, $\mathrm{SCI}>0$ ) for each of the management scenario combinations of tillage type, cover crop, and vegetative barriers

Analysis scenario

Sustainable removal maintaining soil resources ${ }^{\mathrm{a}}$

Nebraska Iowa Illinois Indiana Minnesota Total

1. Billion Ton Update baseline: no cover crop, no vegetative barrier, current tillage Total corn stover available (million $\mathrm{Mg}$ ) Average removal rate $\left(\mathrm{Mg} \mathrm{ha}^{-1}\right)$

2. LEAF baseline: no cover crop, no vegetative barrier, current tillage Total corn stover available (million $\mathrm{Mg}$ ) Average removal rate $\left(\mathrm{Mg} \mathrm{ha}^{-1}\right)$

3. LEAF: cover crop, no vegetative barrier, current tillage

Total corn stover available (million $\mathrm{Mg}$ )

Average removal rate $\left(\mathrm{Mg} \mathrm{ha}^{-1}\right)$

4. LEAF: no cover crop, vegetative barrier, current tillage

Total corn stover available (million $\mathrm{Mg}$ )

Average removal rate $\left(\mathrm{Mg} \mathrm{ha}^{-1}\right)$

5. LEAF: cover crop, vegetative barrier, current tillage

Total corn stover available (million $\mathrm{Mg}$ )

Average removal rate $\left(\mathrm{Mg} \mathrm{ha}^{-1}\right)$

\begin{tabular}{|c|c|c|c|c|c|}
\hline 13.6 & 20.8 & 11.0 & 4.6 & 6.8 & 56.8 \\
\hline 4.3 & 4.8 & 4.4 & 4.3 & 4.1 & 4.4 \\
\hline 17.5 & 23.6 & 26.3 & 11.8 & 17.0 & 96.2 \\
\hline 4.9 & 4.5 & 5.4 & 5.3 & 5.7 & 5.1 \\
\hline 29.0 & 36.8 & 38.3 & 16.7 & 24.6 & 145.4 \\
\hline 8.2 & 7.0 & 7.9 & 7.5 & 8.2 & 7.7 \\
\hline 20.2 & 31.6 & 33.2 & 13.8 & 22.3 & 121.0 \\
\hline 5.7 & 6.0 & 6.8 & 6.2 & 7.5 & 6.4 \\
\hline 32.9 & 45.1 & 43.6 & 18.5 & 28.3 & 168.2 \\
\hline 9.3 & 8.5 & 9.0 & 8.2 & 9.5 & 8.9 \\
\hline 23.0 & 30.1 & 30.3 & 11.4 & 24.1 & 118.8 \\
\hline 6.5 & 5.7 & 6.2 & 5.1 & 8.0 & 6.3 \\
\hline 16.8 & 26.3 & 26.8 & 9.6 & 21.8 & 101.3 \\
\hline 4.8 & 5.0 & 5.5 & 4.3 & 7.3 & 5.4 \\
\hline 29.1 & 40.4 & 38.3 & 14.9 & 28.1 & 150.7 \\
\hline 8.2 & 7.6 & 7.9 & 6.6 & 9.4 & 8.0 \\
\hline 38.9 & 52.9 & 48.8 & 20.4 & 29.7 & 190.6 \\
\hline 11.0 & 10.0 & 10.0 & 9.1 & 10.4 & 10.2 \\
\hline 25.9 & 43.8 & 41.6 & 16.7 & 26.1 & 154.0 \\
\hline 7.3 & 8.3 & 8.6 & 7.5 & 9.1 & 8.2 \\
\hline 39.0 & 54.7 & 49.9 & 21.0 & 29.7 & 194.2 \\
\hline 11.1 & 10.3 & 10.3 & 9.4 & 10.4 & 10.3 \\
\hline
\end{tabular}

6. LEAF: cover crop, no vegetative barrier, reduced tillage

Total corn stover available (million $\mathrm{Mg}$ )

Average removal rate $\left(\mathrm{Mg} \mathrm{ha}^{-1}\right)$

7. LEAF: no cover crop, vegetative barrier, reduced tillage

Total corn stover available (million $\mathrm{Mg}$ )

Average removal rate $\left(\mathrm{Mg} \mathrm{ha}^{-1}\right)$

8. LEAF: cover crop, vegetative barrier, reduced tillage

Total corn stover available (million $\mathrm{Mg}$ )

Average removal rate $\left(\mathrm{Mg} \mathrm{ha}^{-1}\right)$

9. LEAF: cover crop, no vegetative barrier, no-tillage

Total corn stover available (million $\mathrm{Mg}$ )

Average removal rate $\left(\mathrm{Mg} \mathrm{ha}^{-1}\right)$

10. LEAF: no cover crop, vegetative barrier, no-tillage

Total corn stover available (million $\mathrm{Mg}$ )

Average removal rate $\left(\mathrm{Mg} \mathrm{ha}^{-1}\right)$

11. LEAF: cover crop, vegetative barrier, no-tillage

Total corn stover available (million $\mathrm{Mg}$ )

Average removal rate $\left(\mathrm{Mg} \mathrm{ha}^{-1}\right)$

${ }^{\text {a }}$ Standard conservation criteria where soil erosion $<T$ value and $\mathrm{SCI}>0$

provides a conservative estimate of potential opportunities for using vegetative buffers to increase sustainable quantities of stover harvest.

\section{Determining Sustainable Removal Rates}

Two sets of criteria were used to establish sustainable stover harvest rates. The first represents standard NRCS conservation planning and is considered sustainable if (1) the combined soil loss from wind and water erosion is $<T$ as reported in SSURGO and (2) soil organic matter is not being depleted, as indicated by a combined SCI factor $>0$. For each removal rate analyzed, simulated wind and water erosion outputs were combined to provide a total erosion value that was tested to be $<T$. The LEAF output for the SCI was then tested to be $>0$. If both of those conditions were met, then the removal rate was considered sustainable.

A second sustainability criterion was applied to be even more rigorous and conservative. This required that (1) soil erosion levels were $<1 / 2 T$ for each soil and (2) the combined SCI factor and SCI-organic matter (OM) subfactor were both positive, indicating that organic matter is, at a minimum, being 


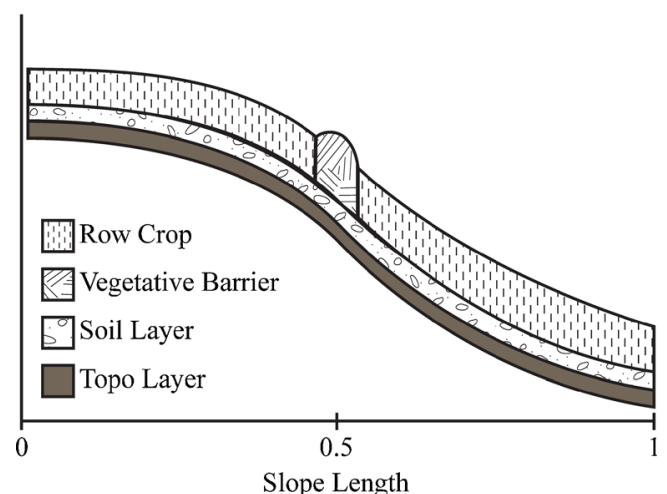

Fig. 1 Representation of a vegetative barrier centered on a slope profile in RUSLE2

maintained at current levels with increasing likelihood that levels will actually increase. This second, more stringent criterion was applied to address concerns that erosion levels approaching $T$ are still significantly higher than soil formation rates [10]. The second target also represents a more conservative approach for ensuring organic matter is not being depleted.

\section{County- and State-Level Residue Quantities}

The maximum sustainable removal rate for each soil-rotationtillage-yield land unit combination was determined using the sustainability metrics on a county-level basis. Each SSURGO soil was given a relative area percentage for each county. All crop rotations, tillage management practices, and conservation management practices for a county were assumed to be evenly distributed across the area for each soil in that county. The county average sustainable stover removal rate, $\mathrm{CR}$, for each management scenario including adoption of a cover crop and/or vegetative barrier is

$$
\mathrm{CR}_{i}=\sum_{j}\left(\alpha_{j} \sum_{k}\left(\beta_{k} \sum_{l}\left(\gamma_{l} c r_{j, k, l}\right)\right)\right)
$$

where $\alpha_{j}$ is the fraction of the area of each $j$ soil, $\beta_{k}$ is the fraction of the area that is in $k$ rotation, $\gamma_{l}$ is the fraction of the area in $l$ tillage regime, and $c r_{j, k, l}$ is the sustainable residue removal rate for $j$ soil in $k$ rotation and $l$ tillage regime. Statelevel sustainably removable residue totals are determined by summing the sustainable residue available in each of the state's counties. All residue quantities are reported in dry metric tons.

\section{Results and Discussion}

Conservation Practices and Large-Scale Residue Removal Opportunities

Two baseline scenarios are presented to relate the results of this study to the standard conservation methods used for the
U.S. Billion Ton Update [1]. Both baseline scenarios use 'current' conservation tillage practices (diverting from the conventional tillage practices of the Billion Ton Update), but neither uses cover crops or vegetative barriers. Both baseline scenarios use the same LEAF tools and methodology, but the Billion Ton Update baseline uses a feedstock price of US\$88.16 $\mathrm{Mg}^{-1}$ to economically motivate participation in residue harvest and the use of specific conservation practices [27]. Economic analysis using POLYSYS resulted in a residue availability of 56.8 million $\mathrm{Mg}\left(4.4 \mathrm{Mg} \mathrm{ha}^{-1}\right)$ for the baseline Billion Ton Update (Table 1; scenario 1). The LEAF baseline analyses (calculated without economic constraints [20]) projected a total sustainable removal of 96.2 million $\mathrm{Mg}$ $\left(5.1 \mathrm{Mg} \mathrm{ha}^{-1}\right.$ ) with the same criteria and practices (Table 1; scenario 2). The 39.4 million $\mathrm{Mg}$ difference between the two baseline scenarios is simply due to inclusion of feedstocks not available at the US $\$ 88.16 \mathrm{Mg}^{-1}$ feedstock price in the Billion Ton Update baseline. Understanding that economically viable and sustainably available residue are not synonymous is an important distinction of the LEAF analyses. Nevertheless, the respective quantity of economically viable residue is believed to increase when the sustainably available quantity is expanded. While the economics are beyond the scope of this work, understanding the impact of conservation management practices represents an important step in our understanding of residue availability for bioenergy.

In contrast to studies by Nelson et al. [44] and Graham et al. [45] where the effect of crop rotation and tillage practice were examined, the objective for this study was to quantify the impact on sustainable corn stover production by also incorporating cover crops and/or vegetative barriers as conservation management practices in the top five corn residue-producing states. Based on the assumptions used, these practices can result in 168 million $\mathrm{Mg}$ of sustainably available corn stover across the five states. Compared to LEAF baseline projections, the use of cover crops within the five states increases sustainable stover harvest rates by $51 \%$ (Table 1 ; scenario 3 ). When only vegetative barriers are added to the landscape, stover availability increases by $26 \%$ compared to the LEAF baseline projections (Table 1; scenario 4). When the two conservation practices are combined, sustainable stover harvest is increased by $75 \%$ within the five states (Table 1; scenario 5). When the states are viewed separately, cover crop practices have the largest impact on sustainable removal rates in Nebraska (67\% increase) and Iowa (56\% increase). Vegetative barrier management practices have the greatest increase in potential removal rates in Iowa (33\% increase) and Minnesota (32\% increase). The combination of both conservation practices has the largest impact in Iowa $(91 \%$ increase) and Nebraska ( $88 \%$ increase) while Indiana receives the lowest, yet still large, improvement (57\% increase).

The effect of widespread adoption of either reduced or no-till management on the availability of corn stover has been 
targeted by several previous modeling assessments and shown to have large positive impacts (upwards of $50 \%$ increases) on sustainably available corn stover $[20,44,45]$. The second goal of this work is to quantify the added benefit of a cover crop and/ or vegetative barriers when applied to lands practicing either reduced or no-tillage under the standard NRCS conservation criteria. The LEAF analyses show that with exclusive reduced tillage management (defined as leaving 15 to $30 \%$ surface cover), the additional conservation practices have a lower impact on sustainable residue availability than lands classified as current tillage. This decrease is primarily the result of changing tillage practices from no- to reduced tillage in some areas. Interestingly, the results indicate that adoption of reduced tillage practices requires simultaneous adoption of vegetative barriers to be comparable to the LEAF baseline (Table 1; scenario 7) and requires a cover crop to exceed the baseline's yield (Table 1; scenarios 6 and 8 ). The greatest potential residue availability is achieved by coupling the cover crop and vegetative barrier practices with no-tillage management. Adoption of only a cover crop when the five states are placed into no-tillage exceeds the production of the current tillage scenario with both a cover crop and vegetative barriers by 22.4 million Mg annually (Table 1 ; scenario 9). This means that 194.2 million $\mathrm{Mg}$ of corn stover are potentially available each year when all three conservation practices are applied. It also reflects a 98 million $\mathrm{Mg}$ annual increase compared to the LEAF baseline, thus emphasizing the

Table 2 Total sustainable corn stover availability and average sustainable removal rates for the top five corn stover-producing states under the rigorous sustainability criteria (erosion $<1 / 2 T$ value, $\mathrm{SCI}$ and SCI-

$\mathrm{OM}>0$ ) for each of the management scenario combinations of tillage type, cover crop, and vegetative barriers. Scenario numbers correspond to those used in Table 1

Analysis scenario

Sustainable removal improving soil resources ${ }^{\mathrm{a}}$

Nebraska Iowa Illinois Indiana Minnesota Total

2S. LEAF baseline: no cover crop, no vegetative barrier, current tillage Total corn stover available (million $\mathrm{Mg}$ ) Average removal rate $\left(\mathrm{Mg} \mathrm{ha}^{-1}\right)$

\begin{tabular}{|c|c|c|c|c|c|}
\hline 9.0 & 10.4 & 6.9 & 1.9 & 8.4 & 36.5 \\
\hline 2.5 & 2.0 & 1.4 & 0.9 & 2.8 & 1.9 \\
\hline 16.6 & 18.4 & 16.6 & 6.5 & 13.7 & 71.9 \\
\hline 4.7 & 3.5 & 3.4 & 2.9 & 4.6 & .8 \\
\hline 14.1 & 17.9 & 15.2 & 5.6 & 13.4 & 66.3 \\
\hline 4.0 & 3.4 & 3.1 & 2.5 & 4.5 & 3.5 \\
\hline 22.6 & 29.9 & 27.8 & 11.2 & 20.5 & 112.0 \\
\hline 6.4 & 5.7 & 5.7 & 5.0 & 6.9 & 5.9 \\
\hline 12.2 & 13.8 & 12.6 & 3.8 & 13.2 & 55.5 \\
\hline 3.5 & 2.6 & 2.6 & 1.7 & 4.4 & 2.9 \\
\hline 10.0 & 13.8 & 11.9 & 3.7 & 13.0 & 52.5 \\
\hline 2.8 & 2.6 & 2.5 & 1.7 & 4.4 & 2 \\
\hline 17.2 & 24.1 & 23.1 & 7.8 & 20.1 & 92.3 \\
\hline 4.9 & 4.6 & 4.8 & 3.5 & 6.7 & 4.9 \\
\hline 24.6 & 31.7 & 23.4 & 8.5 & 18.5 & 106.6 \\
\hline 7.0 & 6.0 & 4.8 & 3.8 & 6.5 & 5.7 \\
\hline 21.6 & 28.8 & 20.7 & 7.0 & 17.0 & 95.0 \\
\hline 6.1 & 5.5 & 4.3 & 3.1 & 5.9 & \\
\hline 31.6 & 44.1 & 34.3 & 13.6 & 24.4 & 148.1 \\
\hline 9.0 & 8.4 & 7.1 & 6.1 & 8.5 & \\
\hline
\end{tabular}

3S. LEAF: cover crop, no vegetative barrier, current tillage

Total corn stover available (million $\mathrm{Mg}$ )

Average removal rate $\left(\mathrm{Mg} \mathrm{ha}^{-1}\right)$

4S. LEAF: no cover crop, vegetative barrier, current tillage

Total corn stover available (million $\mathrm{Mg}$ )

Average removal rate $\left(\mathrm{Mg} \mathrm{ha}^{-1}\right)$

5S. LEAF: cover crop, vegetative barrier, current tillage

Total corn stover available (million $\mathrm{Mg}$ )

Average removal rate $\left(\mathrm{Mg} \mathrm{ha}^{-1}\right)$

6S. LEAF: cover crop, no vegetative barrier, reduced tillage

Total corn stover available (million $\mathrm{Mg}$ )

Average removal rate $\left(\mathrm{Mg} \mathrm{ha}^{-1}\right)$

7S. LEAF: no cover crop, vegetative barrier, reduced tillage

Total corn stover available (million $\mathrm{Mg}$ )

Average removal rate $\left(\mathrm{Mg} \mathrm{ha}^{-1}\right)$

8S. LEAF: cover crop, vegetative barrier, reduced tillage

Total corn stover available (million $\mathrm{Mg}$ )

Average removal rate $\left(\mathrm{Mg} \mathrm{ha}^{-1}\right)$

9S. LEAF: cover crop, no vegetative barrier, no-tillage

Total corn stover available (million $\mathrm{Mg}$ )

Average removal rate $\left(\mathrm{Mg} \mathrm{ha}^{-1}\right)$

10S. LEAF: no cover crop, vegetative barrier, no-tillage

Total corn stover available (million $\mathrm{Mg}$ )

Average removal rate $\left(\mathrm{Mg} \mathrm{ha}^{-1}\right)$

11S. LEAF: cover crop, vegetative barrier, no-tillage

Total corn stover available (million $\mathrm{Mg}$ )

Average removal rate $\left(\mathrm{Mg} \mathrm{ha}^{-1}\right)$

${ }^{a}$ Rigorous conservation criteria where soil erosion $<1 / 2 T$ value, $\mathrm{SCI}$ and SCI-OM $>0$ 
potential benefits of conservation management (Table 1; scenario 11). We recognize that several agronomic challenges exist with this combination of management practices but, nonetheless, the LEAF analysis shows that significant residue removal opportunities will exist when and where these conservation practices can be implemented.

\section{Effects of More Rigorous Sustainability Metrics}

The analyses discussed previously follow typical conservation criteria set by the NRCS and commonly utilized by various research efforts to classify management as maintaining soil quality. In an effort to understand the shift in stover availability as the standards are pushed towards improving soil quality, each of the ten LEAF analyses was evaluated with a more rigorous set of sustainability criteria (total erosion $<1 / 2 T$, $\mathrm{SCI}>0$, and SCI-OM $>0$ ). This causes the sustainably available quantity of corn stover to be significantly reduced in all cases (Table 2, where scenario numbers denoted with ' $S$ ' correspond to those in Table 1). In the LEAF baseline scenario, the total available corn stover across the five states is 37 million $\mathrm{Mg}$, a $62 \%$ decrease compared to the standard criteria (Table 1; scenario 2S). However, the implementations of the cover crop and vegetative barrier conservation practices have a larger impact on potential stover availability under the more rigorous criteria. The use of a cover crop increases the total residue available by $97 \%$ compared to the baseline (Table 2; scenario 3S), up from the $51 \%$ increase achieved with the standard sustainability criteria (Table 1 ; scenario 3 ). Implementing a cover crop and vegetative barriers, even with the rigorous sustainability criteria, increases the total potentially available corn stover within the five states to 112 million $\mathrm{Mg}$, a $207 \%$ increase in sustainable residue potential from the baseline (Table 2; scenario $5 \mathrm{~S}$ ). The reduced tillage scenarios decrease stover availability for the same reason discussed for the standard criteria while no-till methods greatly increase stover availability. In the case of notill management with a cover crop and vegetative barriers, the analysis estimates a potential of 148.1 million $\mathrm{Mg}$ of stover to be sustainably available (Table 2; scenario 11S). These impacts show that the conservation practices have great potential to alleviate additional stressors that may be introduced by stover harvest while still providing a significant opportunity for sustainable access to a large bioenergy resource.

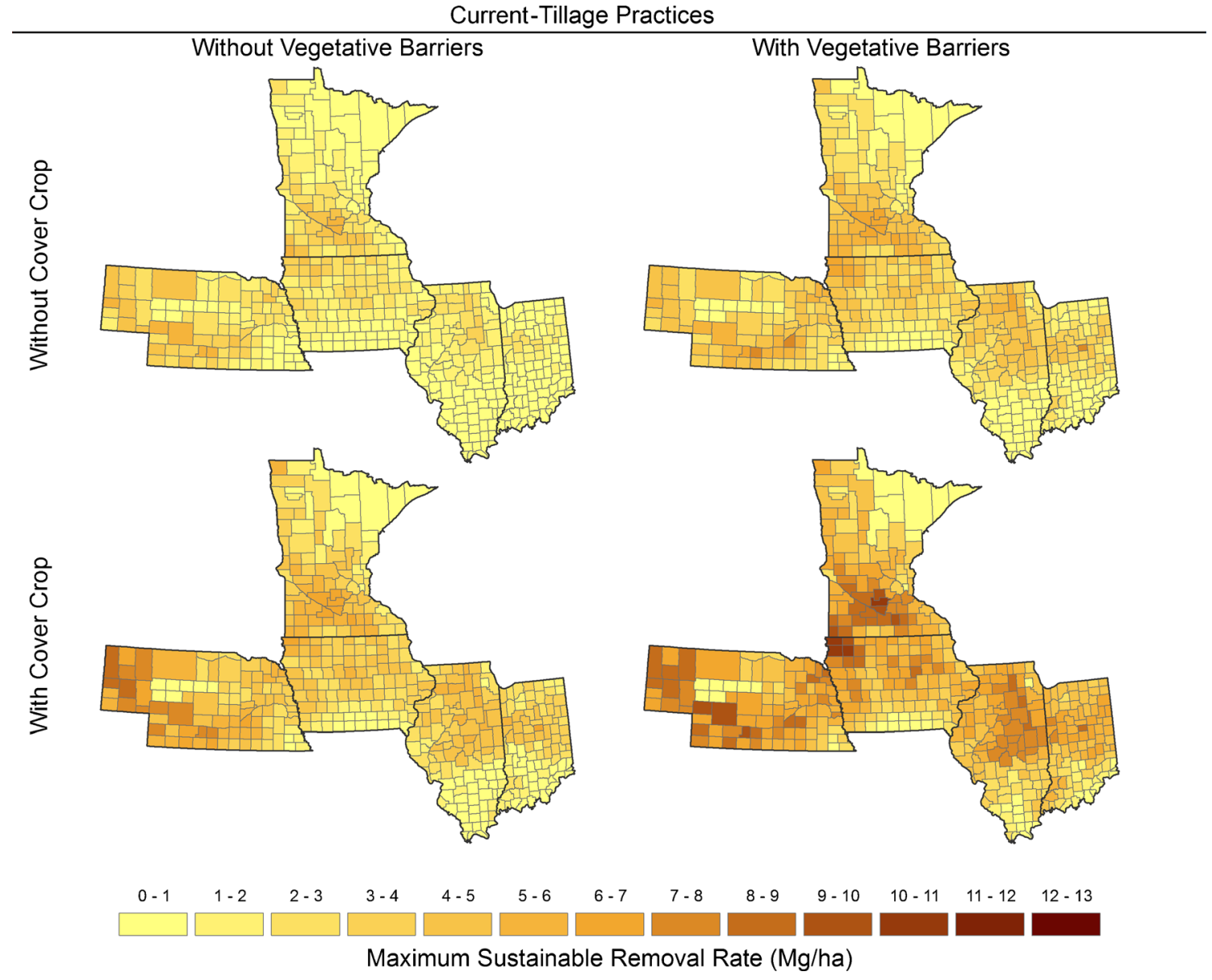

Fig. 2 LEAF-generated maximum sustainable corn stover harvest rates under rigorous conservation criteria (erosion $<1 / 2 T$ value, SCI and SCI-OM $>0$ ) for current tillage management practices when a cover crop and vegetative barriers are incorporated into the landscape 
Spatial depictions on a county-level scale show the distribution and transformation of high- and low-production areas as management scenarios shift between tillage practices and the various combinations of the cover crop and vegetative barrier conservation practices under the rigorous conservation criteria (Figs. 2, 3, and 4). Under the current tillage practices, counties further west receive a larger benefit from cover crop practices, while some counties further east receive additional benefits from vegetative buffer practices (Fig. 2). This is reasonable considering the substantial increase in annual rainfall moving across these states from west to east. In nearly all counties, there is a positive impact by combining the conservation practices. Under the reduced tillage scenario without the cover crop or vegetative barrier conservation practices, the removal rates are generally less than $3 \mathrm{Mg} \mathrm{ha}^{-1}$ (Fig. 3). When both conservation practices are implemented, the western counties in the reduced tillage scenario closely resemble those in the comparable current tillage scenario, while many of the eastern counties show less improvement. The heterogeneity in the results for this set of scenarios stresses the importance of properly selecting conservation management practices and assessing realistic stover availabilities when a reduced tillage system is employed. Nevertheless, numerous counties within the reduced tillage scenarios are capable of sustainably producing upwards of $6 \mathrm{Mg} \mathrm{ha}^{-1}$, an exciting opportunity considering the strict conservation criteria set. Moving to notillage increases the sustainable removal rates across the majority of the five-state area with many counties exceeding $60 \%$ collection efficiency (Fig. 4). Again, it is recognized that in many counties zero-tillage practices may not be operationally feasible. This is represented to some extent by certain counties in Nebraska and Minnesota that lack no-tillage data. As stated previously, these analyses are focused on identifying opportunities created by adoption of additional conservation practices on lands across a range of tillage intensities. Therefore, the practical implementation of the no-till scenarios can be represented simply as minimum tillage.

\section{Conservation Practices and Soil Characteristic Relationships}

Muth et al. [46] identified the impact of subfield scale variability in soil characteristics, surface slope, and grain yield on sustainable residue removal rates and concluded that portions of a field may be unsustainably harvested despite following

\section{Reduced-Tillage Practices}

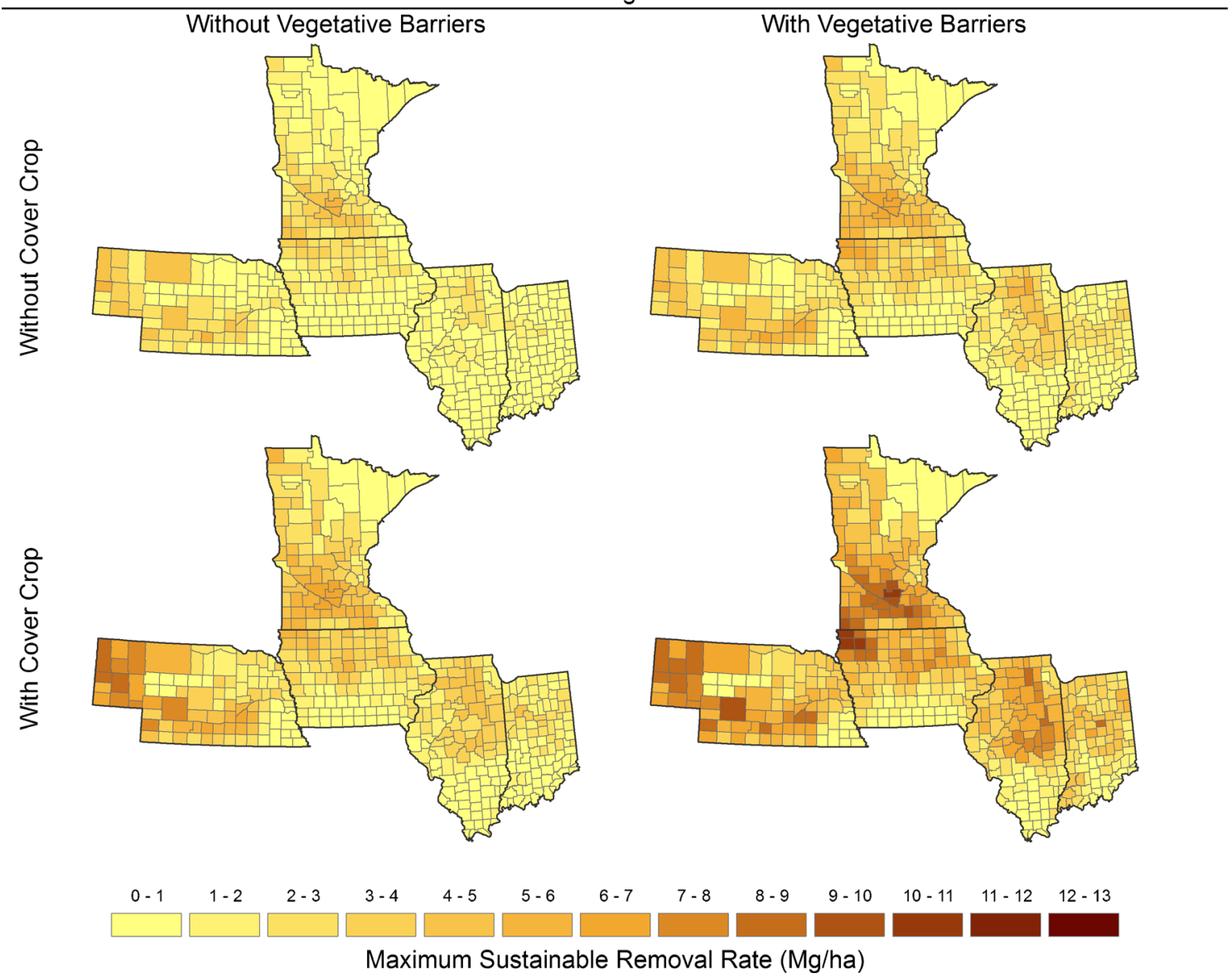

Fig. 3 LEAF-generated maximum sustainable corn stover harvest rates under rigorous conservation criteria (erosion $<1 / 2 T$ value, $\mathrm{SCI}$ and $\mathrm{SCI}-\mathrm{OM}>0$ ) for reduced tillage management practices when a cover crop and vegetative barriers are incorporated into the landscape 


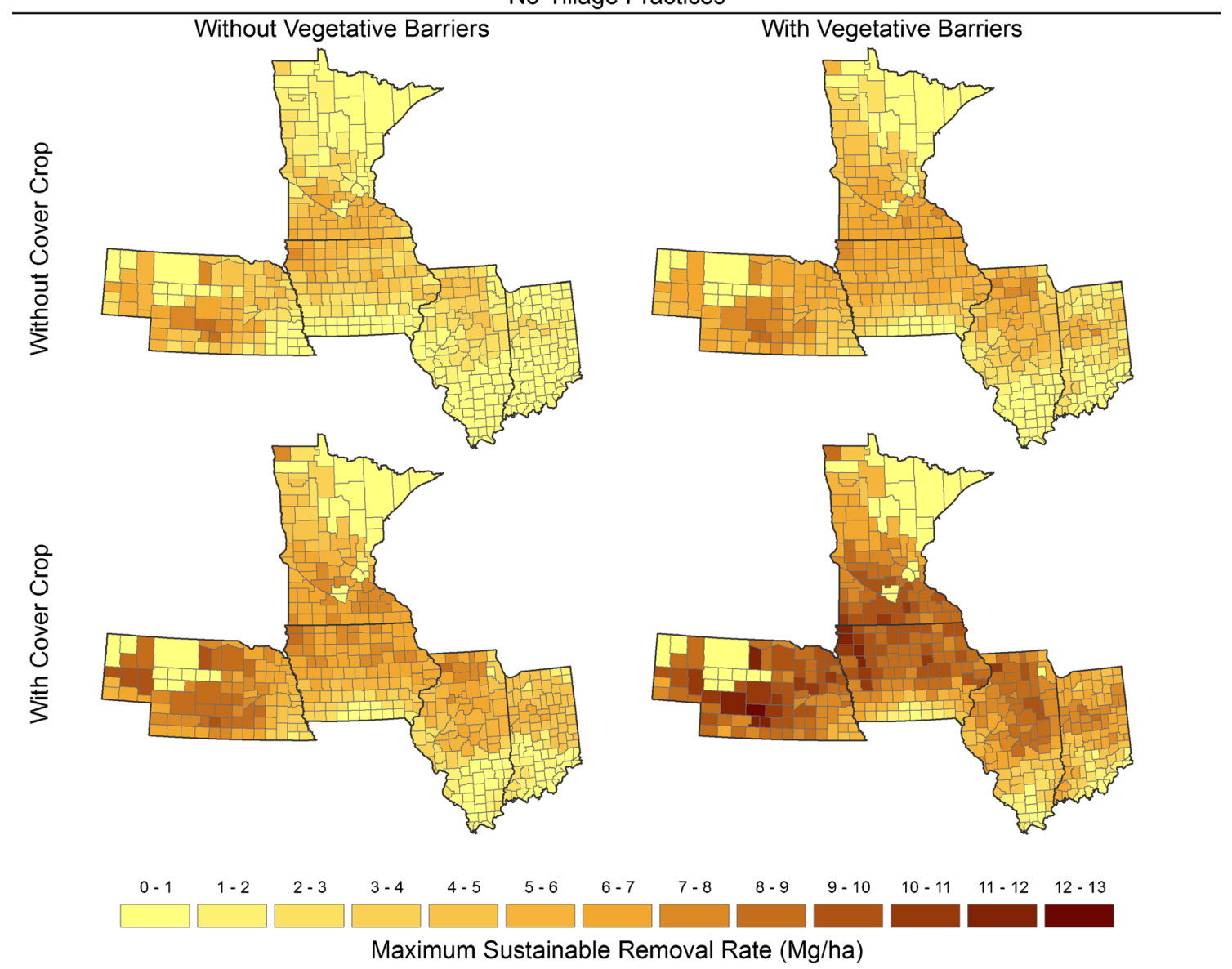

Fig. 4 LEAF-generated maximum sustainable corn stover harvest rates under rigorous conservation criteria (erosion $<1 / 2 T$ value, $\mathrm{SCI}$ and $\mathrm{SCI}-\mathrm{OM}>0$ ) for no-tillage management practices when a cover crop and vegetative barriers are incorporated into the landscape

sustainable field-average assessments. This conclusion creates a challenge to sustainable stover harvest in that residue removal practices must account for the inherent variability present in most agricultural lands. The final objective of this study examines how the conservation practices discussed thus far impact sustainable residue potential across different soil and surface slope characteristics from the five states.

The average sustainable corn stover harvest rate for each of the five states was used to create a composite average of each soil capability class by crop rotation, with error bars representing the range of state average removal rates (Fig. 5). Without a cover crop or vegetative barriers, the rotations including soybeans result in lower sustainable yields when compared to continuous corn, agreeing with the assessment by Nelson et al. [44] where stover availability was reduced by $8 \%$ when the five-state region was switched from continuous corn to corn-soybean. For all states and crop rotations, adoption of a cover crop has a significant impact for soils in capability classes 1-3 (Fig. 5; middle). In most cases, the state-to-state variability increases as soil capability class increases, a result of differences in each state's topography, indigenous soil types, and climate. The large interstate variability in soil capability class 4 is caused by high predicted stover harvest rates in Nebraska and Minnesota resulting from a limited set of capability class 4 soils in these two states. Because of this, the comparison split out by capability class is impacted significantly by a small group of soils supporting higher removal rates in those states. Further analysis is required to better understand this response and better manage the model scenario to properly represent soil capability classes when their relative representation is small. In all other cases, the capability class 4 soils using cover crop practices are limited in sustainable removal potential, as would be expected. Vegetative barriers in general do not independently provide as much benefit as that of the cover crop practices, but do increase the removal rate of rotations including soybean to levels similar to continuous corn for soil capability classes 1 and 2 (Fig. 5; bottom). One key conclusion is that residue removal needs to be done cautiously for soils in capability classes 3 and 4 , respecting differences in performance due to crop rotation and state. The use of the cover crop and vegetative barrier conservation practices can support increased removal on capability class 3 soils, and while increased removal can be supported in certain circumstances on capability class 4 soils, added caution may still be required. 

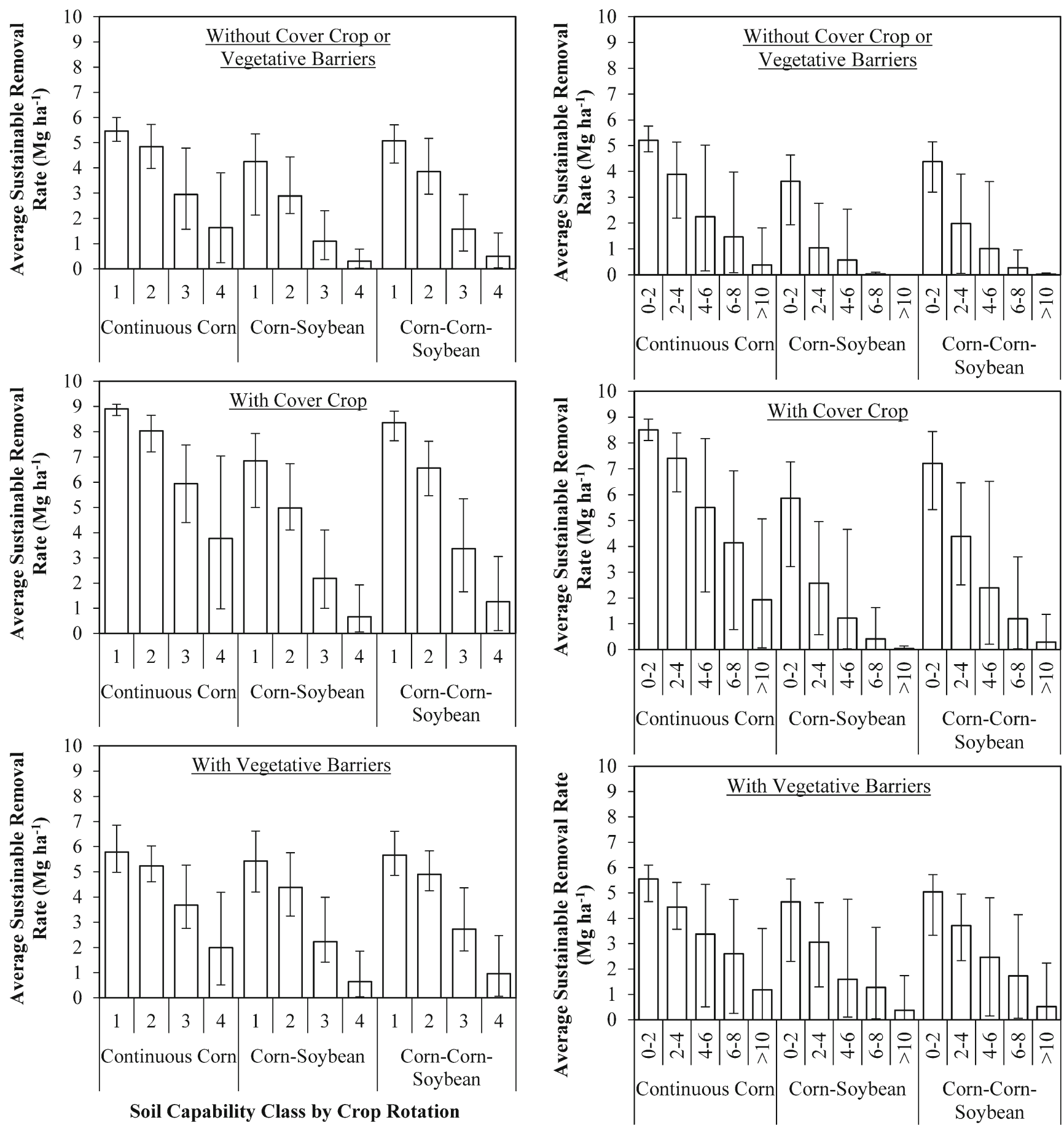

Fig. 5 Influence of cover crop and vegetative barrier conservation practices on average sustainable corn stover harvest rate under the standard conservation criteria (erosion $<T$ value, $\mathrm{SCI}>0$ ) by soil capability class and crop rotation for the five states studied. Error bars represent the range of state average removal rates. Rates normalized to corn harvest years only

A similar set of analyses were performed to investigate the impact of slope on corn stover availability under the standard conservation criteria by aggregating the five states into an average based on slope category and depicting the interstate range with error bars (Fig. 6). Without conservation practices,

Fig. 6 Influence of cover crop and vegetative barrier conservation practices on average sustainable corn stover harvest rate under the standard conservation criteria (erosion $<T$ value, $\mathrm{SCI}>0$ ) by soil slope and crop rotation for the five states studied. Error bars represent the range of state average removal rates. Rates normalized to corn harvest years only

sustainable residue removal is shown to be challenging on slopes $>4 \%$; this is particularly true for the soybean rotations, where interstate variability becomes quite large even at slopes $>2 \%$ (Fig. 6; top). Minnesota and Nebraska, under a 

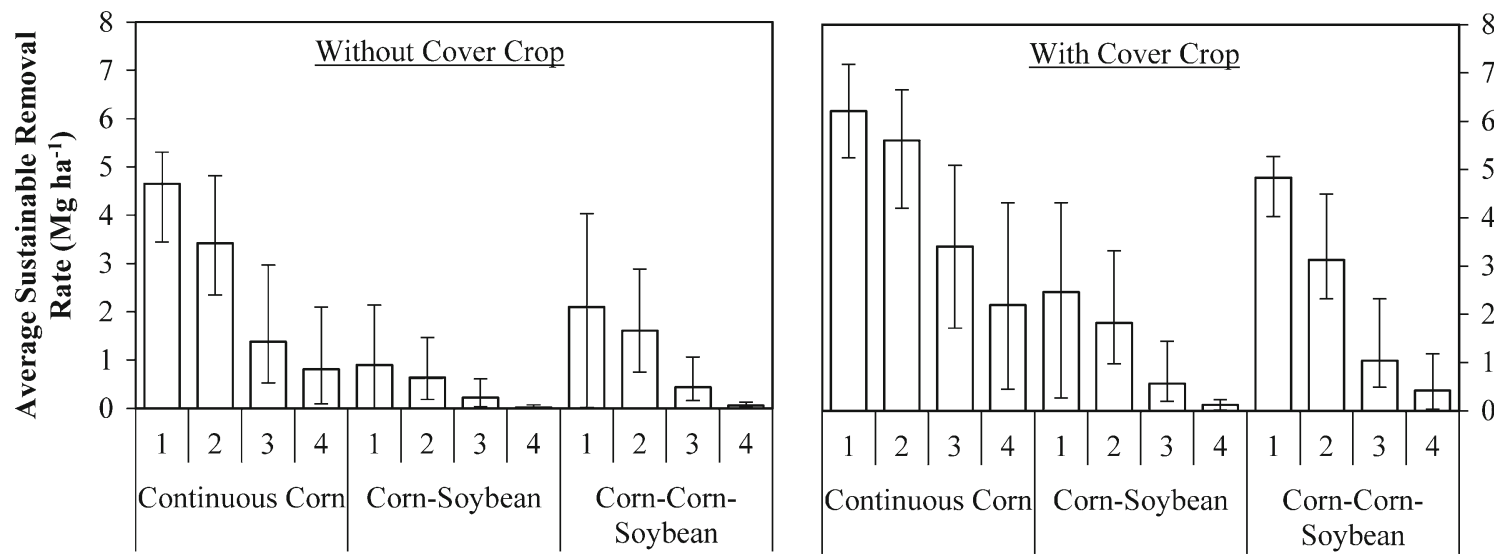

Soil Capability Class and Crop Rotation

Fig. 7 Influence of cover crops on sustainable corn stover harvest rate under the rigorous conservation criteria (erosion $<1 / 2 T$ value, $\mathrm{SCI}$ and SCI-OM $>0$ ) by soil capability class and crop rotation across the top five

continuous corn rotation, are the only instances able to support significant sustainable removal across higher surface slopes, again likely due to these states' reduced dataset under these conditions, potentially skewing the results. When cover crop practices are included, the sustainable removal rates are increased for all states across higher slopes using a continuous corn rotation, though the variability between states remains extreme (Fig. 6; middle). The impact of adopting cover crop management practices on sustainable removal rates for higher slopes is much less for the corn-soybean rotation where collection rates for slopes $>4 \%$ remain relatively low and variable between states. Again, vegetative barrier practices independently have less impact on sustainable removal potential than cover crops across all slope and crop rotation scenarios (Fig. 6; bottom). However, vegetative barriers do support a greater increase in removal rate for corn-soybean and corncorn-soybean rotation scenarios at slope ranges greater than $4 \%$ than the cover crop scenarios. This is likely due to the residue-producing states. Error bars represent the range of state average removal rates. Rates normalized to corn harvest years only

vegetative barrier's ability to reduce water erosion potential on high soil slopes during wet periods where cover crops have either not fully established in the fall or have been killed in the spring in anticipation for planting. Despite this slight increase, significant residue removal on slopes greater than $4 \%$ and crop rotations that include soybeans will often need to include the conservation practices investigated in this study.

These same methods of comparison were applied to the results of the more rigorous conservation criteria for adoption of cover crop management practices. Improvements are again seen in sustainable removal rates on soil capacity classes 1-3 for each of the three crop rotations without substantial increases in interstate variability (Fig. 7). The use of a cover crop on soils of capability class 4 in the continuous corn rotation has a relatively large increase in sustainable corn stover harvest rates, but state-to-state variability becomes a serious concern. The sustainable residue removal rates are significantly increased on soils of capability classes 1 and 2
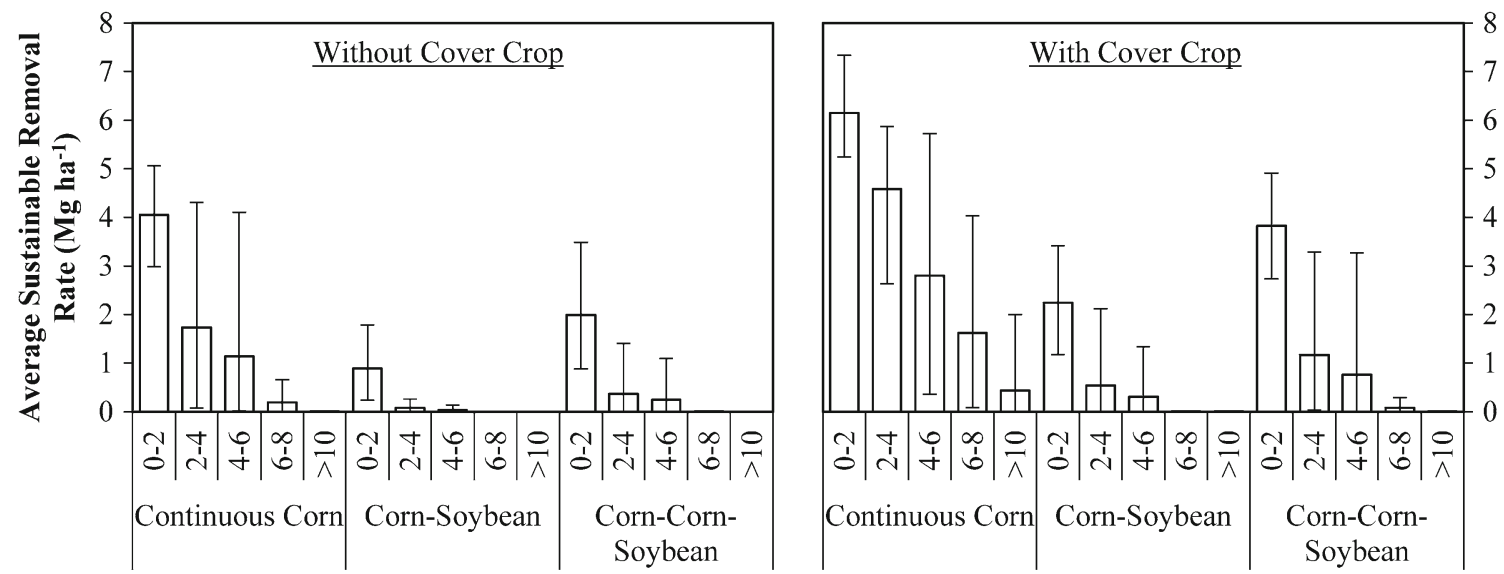

Soil Slope Grade (\%) and Crop Rotation

Fig. 8 Influence of cover crops on sustainable corn stover harvest rate under the rigorous conservation criteria (erosion $<1 / 2 T$ value, SCI and $\mathrm{SCI}-\mathrm{OM}>0$ ) by soil slope and crop rotation across the top five residue- producing states. Error bars represent the range of state average removal rates. Rates normalized to corn harvest years only 
in rotations that include soybean. Sustainable corn stover harvest rates become highly limited when slopes exceed $2 \%$ in a continuous corn rotation without a cover crop, and soybean-containing rotations allow for little corn stover collection even on $<2 \%$ slopes without a cover crop (Fig. 8). Adoption of cover crops shows a dramatic response in residue removal rates, with slopes up to $6 \%$ in a continuous corn rotation yielding significant amounts of corn stover while soybean rotations begin to provide sustainable residue on low slope surfaces. The amount of interstate variability is quite large despite these increases however, indicating that sitespecific considerations are crucial for successful application of cover crops for promoting sustainable residue collection. The results of this analysis show that even when rigorous conservation criteria are set, large amounts of corn stover may be collected when landscape characteristics are taken into consideration. Furthermore, these results stress the importance of designing management practices to suit a specific agricultural land unit, as demonstrated by the sensitivity of potential corn stover harvest rates based on state, soil capacity class, and slope.

\section{Conclusions}

The use of cover crops and vegetative barriers along with no-till management can increase sustainable corn stover availability from 96.2 million $\mathrm{Mg}$ annually to 194.2 million $\mathrm{Mg}$ annually within the five-state study region under standard NRCS sustainability criteria. The potential quantity of harvestable corn stover is reduced to 148.1 million $\mathrm{Mg}$ annually when more rigorous sustainability criteria are applied. Challenges remain with soils of capability class 4 and slopes greater than $4 \%$, particularly for crop rotations that include soybean. Therefore, sustainable residue removal decisions must be made considering field characteristics at the subfield scale rather than with field or, worse yet, county averages. Overall, however, these conservation practices provide a robust set of choices and opportunities for overcoming the challenges of variability in making consistently sustainable residue removal decisions.

Acknowledgments This work is supported by the U.S. Department of Energy, under DOE Idaho Operations Office Contract DE-AC0705ID14517. Accordingly, the U.S. Government retains a nonexclusive, royalty-free license to publish or reproduce the published form of this contribution, or allow others to do so, for U.S. Government purposes. The authors also acknowledge Dr. Wally Tyner, Michelle Pratt, and Alicia English from Purdue University for their collaboration designing the conservation management strategies implemented in this analysis.

U.S. Department of Energy Disclaimer This information was prepared as an account of work sponsored by an agency of the U.S. Government. Neither the U.S. Government nor any agency thereof, nor any of their employees, makes any warranty, express or implied, or assumes any legal liability or responsibility for the accuracy, completeness, or usefulness of any information, apparatus, product, or process disclosed, or represents that is use would not infringe privately owned rights. References herein to any specific commercial product, process, or service by trade name, trademark, manufacturer, or otherwise, does not necessarily constitute or imply its endorsement, recommendation, or favoring by the U.S. Government or any agency thereof. The views and opinions of authors expressed herein do not necessarily state or reflect those of the U.S. Government or any agency thereof.

Open Access This article is distributed under the terms of the Creative Commons Attribution License which permits any use, distribution, and reproduction in any medium, provided the original author(s) and the source are credited.

\section{References}

1. U.S. Department of Energy (DOE) (2011) U.S. Billion Ton Update: biomass supply for a bioenergy and bioproducts industry. R.D. Perlack and B.J. Stokes (Leads), ORNL/TM-2011/224. Oak Ridge National Laboratory, Oak Ridge, TN. 227p. www.bioenergykdf.net/ content/billiontonupdate. Accessed 9 Jan 2014

2. Hess JR, Kenney KL, Wright CT, Perlack R, Turhollow A (2009) Corn stover availability for biomass conversion: situation analysis. Cellulose 16(4):599-619. doi:10.1007/s10570-009-9323-z

3. Congress US (2007) Energy independence and security act of 2007. Public Law (110-140):2. www.govtrack.us/congress/bills/110/ hr116. Accessed 9 Jan 2014

4. Humbird D, Davis R, Tao L, Kinchin C, Hsu D, Aden A, Schoen P, Lukas J, Olthof B, Worley M, Sexton D, Dudgeon D (2011) Process design and economics for biochemical conversion of lignocellulosic biomass to ethanol. National Renewable Energy Laboratory Technical Report NREL. TP-5100-47764. http://www.nrel.gov/ biomass/pdfs/47764.pdf. Accessed 9 Jan 2014

5. Reijnders L (2006) Conditions for the sustainability of biomass based fuel use. Energy Policy 34(7):863-876

6. Andrews SS (2006) Crop residue removal for biomass energy production: effects on soils and recommendations. Soil Quality Agronomy Technical Note 19. White paper, USDA Natural Resources Conservation Service, Washington DC. http://www.nrcs. usda.gov/Internet/FSE_DOCUMENTS/nrcs142p142_053255.pdf. Accessed 9 Jan 2014

7. Wilhelm WW, Hess RJ, Karlen DL, Johnson JMF, Muth DJ, Baker JM, Gollany HT, Novak JM, Stott DE, Varvel GE (2010) Review: balancing limiting factors \& economic drivers for sustainable Midwestern US agricultural residue feedstock supplies. Ind Biotechnol 6(5):271-287

8. Wilhelm WW, Johnson JMF, Hatfield JL, Voorhees WB, Linden DR (2004) Crop and soil productivity response to corn residue removal: a literature review. Agron J 96(1):1-17

9. Wilhelm WW, Johnson JMF, Karlen DL, Lightle DT (2007) Corn stover to sustain soil organic carbon further constrains biomass supply. Agron J 99(6):1665-1667

10. Montgomery DR (2007) Soil erosion and agricultural sustainability. Proc Natl Acad Sci 104(33):13268-13272

11. Blanco-Canqui H, Lal R (2007) Soil and crop response to harvesting corn residues for biofuel production. Geoderma 141(3-4):355-362

12. ASAE (2004) Terminology and definitions for agricultural tillage implements, S414.1 FEB04. American Society of Agricultural Engineers, St. Joseph

13. Allmaras RR, Linden DR, Clapp CE (2004) Corn-residue transformations into root and soil carbon as related to nitrogen, tillage, and stover management. Soil Sci Soc Am J 68(4):1366-1375 
14. Reicosky DC, Kemper WD, Langdale GW, Douglas CL, Rasmussen PE (1995) Soil organic matter changes resulting from tillage and biomass production. J Soil Water Conserv 50(3):253-261

15. Clapp CE, Allmaras RR, Layese MF, Linden DR, Dowdy RH (2000) Soil organic carbon and $13 \mathrm{C}$ abundance as related to tillage, crop residue, and nitrogen fertilization under continuous corn management in Minnesota. Soil Tillage Res 55(3-4):127-142

16. House GJ, Parmelee RW (1985) Comparison of soil arthropods and earthworms from conventional and no-tillage agroecosystems. Soil Tillage Res 5(4):351-360

17. Karlen DL (2011) Potential soil quality impact of harvesting crop residues for biofuels. Agrociencia Mag 15(2):120-127

18. Karlen DL, Varvel GE, Johnson JMF, Baker JM, Osborne SL, Novak JM, Adler PR, Roth GW, Birrell SJ (2011) Monitoring soil quality to assess the sustainability of harvesting corn stover. Agron J 103(1): 288-295

19. Karlen DL, Birell SJ, Hess JR (2011) A five-year assessment of corn stover harvest in central Iowa, USA. Soil Tillage Res 115:47-55

20. Muth DJ, Bryden KM, Nelson RG (2013) Sustainable agricultural residue removal for bioenergy: a spatially comprehensive US national assessment. Appl Energy 102:403-417

21. Muth DJ, Bryden KM (2013) An integrated model for assessment of sustainable agricultural residue removal limits for bioenergy systems. Environ Model Softw 39:50-69

22. De La Torre Ugarte DG, Ray DE (2000) Biomass and bioenergy applications of the POLYSYS modeling framework. Biomass Bioenergy 18(4):291-308

23. Dabney SM, Delgado JA, Reeves DW (2001) Using winter cover crops to improve soil and water quality. Commun Soil Sci Plant Anal 32(7-8):1221-1250

24. Meki MN, Snider JL, Kiniry JR, Raper RL, Rocateli AC (2013) Energy sorghum biomass harvest thresholds and tillage effects on soil organic carbon and bulk density. Ind Crop Prod 43:172-182

25. Lankoski J, Ollikainen M, Uusitalo P (2006) No-till technology: benefits to farmers and the environment? Theoretical analysis and application to Finnish agriculture. Eur Rev Agric Econ 33(2):193221

26. Hartwig NL, Ammon HU (2002) Cover crops and living mulches. Weed Sci 50(6):688-699

27. English A, Tyner WE, Sesmero J, Owens P, Muth DJ (2013) Environmental tradeoffs of stover removal and erosion in Indiana. Biofuels Bioprod Biorefin 7(1):78-88

28. Yuan Y, Bingner RL, Locke MA (2009) A review of effectiveness of vegetative buffers on sediment trapping in agricultural areas. Ecohydrology 2(3):321-336

29. Blanco-Canqui H, Gantzer CJ, Anderson SH, Alberts EE, Thompson AL (2004) Grass barrier and vegetative filter strip effectiveness in reducing runoff, sediment, nitrogen, and phosphorus loss. Soil Sci Soc Am J 68(5):1670-1678

30. Revised Universal Soil Loss Equation, Version 2 (RUSLE2). Official NRCS RUSLE2 Program. Washington, DC: USDA Natural Resource Conservation Service and USDA Agricultural Research Service. http://fargo.nserl.purdue.edu/rusle2_dataweb/RUSLE2 Index.htm. Accessed 9 Jan 2014
31. Official NRCS-WEPS Site. Wind Erosion Prediction System. Washington, DC: USDA Agricultural Research Service and USDA Natural Resource Conservation Service. http://www.weru.ksu.edu/ nrcs/wepsnrcs.html. Accessed 9 Jan 2014

32. Soil Conditioning Index. USDA: Natural Resources Conservation Service. http://www.nrcs.usda.gov/wps/portal/nrcs/detail/ia/ newsroom/factsheets/?cid=nrcs142p2 008548. Accessed 9 Jan 2014

33. USDA announces new conservation collaboration with DuPont to promote sustainable harvesting of bio-based feedstocks for cellulosic ethanol. Release No. 0058.13. U.S. Department of Agriculture. Washington, D.C. http://www.usda.gov/wps/portal/usda/usdahome? contentid=2013/03/0058. $x m$ l\&contentidonly $=$ true. Accessed 9 Jan 2014

34. Regional Biomass Feedstock Partnership executive summary (2011) SunGrant/Department of Energy Office of Biomass Programs. http:/ www.sungrant.org/Feedstock+Partnerships/. Accessed 9 Jan 2014

35. Karlen DL, Muth DJ (2013) Landscape management for sustainable supplies of bioenergy feedstock and enhanced soil quality. Agrociencia (In Press; Accepted August, 2013)

36. USDA-NRCS (1998) Key to soil taxonomy, 8th edn. National Soil Survey Publication, Washington, DC

37. USDA-NRCS (2001) Soil quality test kit guide. USDA-NRCS Soil Quality Institute, Ames

38. Description of SSURGO Database. USDA Natural Resource Conservation Service. http://www.nrcs.usda.gov/wps/portal/nres/ detail/soils/survey/?cid=nrcs142p2 053627. Accessed 9 Jan 2014

39. Crop Land Data Layer. Washington, DC: USDA National Agricultural Statistics Service, Research and Development Division. http://www.nass.usda.gov/research/Cropland/SARS1a. $\mathrm{htm}$. Accessed 9 Jan 2014

40. The USDA/NASS 2010 Cropland Data Layer: 48 state continental US coverage. Washington, DC: USDA National Agricultural Statistics Service. http://www.nass.usda.gov/research/Cropland/ Method/cropland.pdf. Accessed 9 Jan 2014

41. Crop management zones. Washington, DC: US Department of Agriculture Natural Resource Conservation Service. http://fargo. nserl.purdue.edu/rusle2 dataweb/NRCS Crop Management Zone_Maps.htm. Accessed 9 Jan 2014

42. Conservation Technology Information Center. West Lafayette (IN): Purdue University. http://www.ctic.purdue.edu/. Accessed 9 Jan 2014

43. Managing cover crops in conservation tillage systems (2007). In: Clark A (ed) Managing cover crops profitably, 3rd edn. Sustainable Agriculture Network, Beltsville, p 44-61

44. Nelson RG, Walsh M, Sheehan JJ, Graham R Methodology for estimating removable quantities of agricultural residues for bioenergy and bioproduct use. In: Proceedings of the twenty-fifth symposium on biotechnology for fuels and chemicals held May 4-7, 2003, in Breckenridge, CO, 2004. Springer, p 13-26.

45. Graham RL, Nelson R, Sheehan J, Perlack R, Wright LL (2007) Current and potential US corn stover supplies. Agron J 99(1):1-11

46. Muth DJ, McCorkle DS, Koch JB, Bryden KM (2012) Modeling sustainable agricultural residue removal at the subfield scale. Agron J 104:970-981. doi:10.2134/agronj2012.0024 